\title{
Ayer y hoy del cosmopolitismo kantiano
}

\author{
JUAN CARLOS VELASCO ARROYO \\ Instituto de Filosofia, CSIC
}

El ideal cosmopolita desarrollado por Kant
en su breve escrito La paz perpetua, publicado
en 1795 , ha gozado de una inmensa influencia
y conserva aún hoy una indiscutible vigencia.
En su formulación original cl ideal kantiano
se encontraba intimamente ligado a la nece-
sidad de encontrar medios adecuados para
superar el estado de guerra en el que la his-
toria humana se ha instalado. Tres son las principales propuestas kantianas al respecto: la formación de gobiernos democráticos, la instauración de una federación de Estados libres y la constitución de un derecho cosmopolita. Estas ideas son examinadas a lo largo del presente artículo a la luz de los problemas de las actuales relaciones internacionales, y con especial referencia a dos recientes textos de Rawls y Habermas.

Algunos pensadores del siglo xvil demostraron la suficiente perspicacia como para advertir que a la filosofía clásica del Estado le restaba aún subir un peldaño más para lograr garantizar la paz en su sentido pleno. Sin este nuevo escalón la teoría política quedaba esencialmente incompleta. El contrato social podría asegurar la paz civil en el interior de los estados, pero dejaba inalterados los motivos de antagonismo y hostilidad entre las diferentes comunidades políticas. De hecho, mantener la estabilidad exterior siempre resultó una necesidad vital para todo Estado que quisiera ser soberano, pues nunca la política interior de colectividad alguna permaneció del todo inmune a los vaivenes de sus vecinos y menos aún a sus conflictos bélicos. Para Thomas Hobbes, autor de una de las concepciones de la política por entonces más influyentes, la preocupación central, casi exclusiva, no era otra, sin embargo, que la seguridad interior. Frente a esa alicorta perspectiva, aquellos pensadores del xvin observaron la conveniencia de adecuar la teoría a la realidad aumentando la amplitud de miras y fijando la atención en el cscenario de las relaciones internacionales. Al establecer esta nueva posición revelaron sin duda una comprensión más profunda de la esfera internacional que la expuesta. en la mecánica política hobbesiana, y esa ventaja les permitió afrontar el problema fundamental de un orden jurídico propiamente dicho entre los Estados. Este cambio debe considerarse, al menos ése es mi propósito, como una ganancia teórica que ofrece herramientas intclectuales para pensar sobre nuestra propia situación. En el mundo de hoy, en donde los márgenes de la comunidad de los hombres se han ampliado enormemente en virtud de la emergencia -entre otros tantos fenómenos- de la aldea global, el estrecho y esencial vínculo entre la política interior y exterior ha alcanzado un relieve sin precedentes.

El célebre ensayo kantiano sobre La paz perpetua publicado en 1795 ocupa un lugar sobresaliente entre las aportaciones dieciochescas antes referidas, algo 
que ha sido destacado con ocasión de su bicentenario ". En el presente artículo se pretende extracr de esa concepción irenista un rendimiento teórico-práctico pertinente para el mundo de hoy y de este modo contribuir a repensar en términos contemporáneos el cosmopolitismo del siglo xvil. Para ello se presentan, en primer lugar, un precedente tan obvio del texto de Kant como es el proyecto del abate Saint-Pierre, ayudado en ello de la mano de Rousseau, que constituye el enlace histórico entre el clérigo galo y el filósofo prusiano. En segundo lugar, se identifican los elementos básicos de la aportación kantiana a la comprensión contemporánea de las relaciones internacionales con el fin de ofrecer algunas claves interpretativas del opúsculo kantiano (aunque no sería mi intención adentrarme aquí en los vericuetos de la hermenéutica textual). $Y$ en tercer lugar se da cuenta de una parte de la reciente recepción de ese texto. Si bien es cierto que a lo largo de la presente centuria las propuestas avanzadas en él no han dejado de ejercer una considerable fascinación teórica, llegando incluso a servir de inspiración a proyectos como el de la Sociedad de Naciones o el de las Naciones Unidas, recientemente pensadores tan influyentes en este final de siglo como John Rawls y Jürgen Habermas han vuelto a resaltar su valor para la formulación de nuevas bases sobre las que asentar el orden internacional.

\section{Algunos antecedentes del opúsculo kantiano}

Entre las fuentes de inspiración de la teoría irenista de Kant así como de su derecho cosmopolita hay que distinguir dos grupos: en primer lugar, los autores que influyeron positivamente en su pensamiento y de los que retomó numerosas intuiciones, y en segundo lugar, aquellos otros con los que no concordaba pero de los que obtenía un importante estímulo, de tal manera que a la larga determinaron la factura final del opúsculo de modo incluso más fecundo que los primeros ${ }^{2}$. Entre las fuentes, por así decir, positivas destacan el abate de Saint-Pierre y Rousseau. Entre los segundos se encuentran los teóricos de la incipiente doctrina del derecho internacional, en especial el suizo Emmer de Vattel, así como los teóricos de la guerra justa.

En los siglos xvil y xvin adquirió particular relevancia un sector doctrinal que se caracterizó por afrontar el problema de la guerra mediante la formulación de proyectos de tratados permanentes de paz. Un modo de proceder que recuerda al propio de los numerosos arbitristas españoles del Siglo de Oro, autores de expedientes y memoriales destinados a poner remedios a los males patrios. La común preocupación por el bien público en su sentido más noble y el que a algunos quepa considerarlos como forjadores de quimeras sirve de apoyo a dicha com-

'Entre las numerosas publjcaciones aparecidas en Alemania con ocasión del bicentenario del texto kantiano, cfr. Bachmann (1996) y Merkel y Wittmann (1996). Y entre las publicadas en España destaca, sin duda, cl volumen colcctivo editado por Aramayo, Muguerza y Roldán (1996).

2 Para un estudio pormenorizado de las fuentes y antecedentes del texto kantiano, cfr. Concha Roldân, "Los "prolegómenos" del proyecto kantiano sobre la paz perpetua», en Aramayo, Muguerza y Roldán (1996), pp. 125-154. 
paración. A ese grupo de arbitristas por la paz, Bobbio (1992, p. 181) los considera conspicuos representantes del iusirenismo o pacifismo juridico, esto es, de la bús* queda de la paz a través del derecho. En todo caso, se trata de una scric de autores -entre los que destacan Saint-Pierre, de alguna manera Vattel, Kant y Bentham- que tras compartir un mismo diagnóstico sobre las continuas y extenuantes guerras como un grave mal social proponen vías diversas para alcanzar y organizar la paz.

El núcleo de la propuesta del abate de Saint-Pierre (1658-1743), ministro plenipotenciario del reino de Francia en las negociaciones de Utrecht (1713) que pusieron fin a la Guerra de Sucesión española, consistía en crear una «Liga de Naciones»y, en concreto, una «Societé permanente de l'Europe», con el objeto de fijar fronteras entre los diferentes Estados del continente de una vez para siempre y de modo obligatorio. Debe recordarse que en el Tratado de Utrecht -reforzando lo ya cstipulado en el Tratado de Westfalia de 1648 - se articuló un sistema europeo basado en el principio de equilibrio de fuerzas (iustum potentiae equilibrium) ${ }^{3}$, a cuya debilidad Saint-Pierre intentó poner remedio. Entre 1713 y 1717 elaboró un voluminoso Project de traité pour rendre la paix perpétuelle entre les souverains Chrétiens o Project de paix perpétuelle. Esta obra merece figurar tanto en la historia de la uidea europea» como en la evolución de la problemática «pacifista». Lo singular de este Projet estriba precisamente en el nexo que establece entre ambos aspectos al presentar la edificación de una sociedad europea como la única garantía de la "perpetuidad de la paz» en los Estados de los «príncipes cristianos». Fsta acotación espacial de sus objetivos revela a las claras la inmersión del autor en las coordenadas mentales de la «Res Publica Christiana». Saint-Pierre proponía de hecho una asociación de los Estados cristianos europeos tal que implicase la renuncia expresa a la guerra como medio de resolver las controversias, la institución del arbitraje obligatorio y una fuerza internacional para mantener la paz y la alianza.

Más allá de su mérito intrínseco, la obra de Saint-Pierre tiene un indudable valor histórico, pues aunque sea más gracias a la mediación de Rousseau que a la lectura del texto original, se erigió en el punto de partida de la filosofía del derecho internacional elaborada por Kant ( $y$, por ende, del joven Fichte). La obra de Saint-Pierre se conoció en toda Europa debido, sin duda, a la atención que le prestara Rousseau, ya que dado el estilo del abate, que carecía de la amenidad propia de su siglo, y a la extensión del proyecto, sin el resumen (inevitablemente libre) del filósofo ginebrino -al que luego añadiría como opúsculo aparte un comentario propio- " nunca hubiera logrado un adecuado nivel de divulgación. Numerosos críticos burlones de la época, entre ellos muchos enciclopedistas, consideraron el proyecto de Saint-Pierre como una clara muestra de irenismo ingenuo y remarcaron la distancia que separaba el planteamiento del clérigo y los pre-

"Según Vartel (1758), ese sistena de equilibrio significaba «un arreglo de los asuntos de manera que ningún Estado tenga predominio absoluto ni domine a todos los demás».

"Se trata del Extracto del Proyecto de Paz Perpetua del Sr. abate de Saint-Pierre» (1761) y del «Iuicio del Proyecto de Paz Perpetua» (1792, ed. postuma), que se encuentran recopilados en Rousseau (1982). Según Klenner (1996), fue a través de estos textos de Rousseau como Kant conoció la obra del abate de Satnt-Pierre, al que cita dos veces en su opusculo. 
supuestos políticos ilustrados: el autor del quimérico proyecto era propenso a un cosmopolitismo muy a tono con la «Europa de los monarcas» $y$, en definitiva, ета un arduo defensor del statu quo. Saint-Pierre, ciertamente, se esforzó en demostrar que su proyecto era favorable al poder de las grandes dinastías soberanas de Europa. Rousseau, que se consideraba un ciudadano ginebrino y tenía la mirada puesta en la «Europa de los pueblos», no ignoraba tampoco esta distancia, que en absoluto consideraba menor, y reprochó además a Saint-Pierre que no tomara en cuenta la tendencia de los príncipes al despotismo. Este punto de discrepancia no fue, empero, óbice para que Rousseau, como ya hiciera con anterioridad Leibniz (1984, pp. 195-200) en sus observaciones al texto del abate, tomara en serio el proyecto y lo considerase de utilidad general. Saint-Pierre puso, de hecho, el dedo en la llaga al señalar el punto flaco de los tratados internacionales: no tenían otros garantes que las partes contratantes. Como afirmaba Rousseau (1982, p. 61), esos acuerdos «no tienen más garantía que la utilidad del que a él se somete; sólo son respetados cuando el interés los confirma». De esa debilidad, que está en el origen de frecuentes guerras, nace la necesidad de «una fuerza coactiva que ordene y concierte los movimientos de sus miembros para dar a los intereses comunes y a los compromisos recíprocos la solidez que no podrían tener por sí mismos» (Rousseau, 1982, p. 9).

El estrecho parentesco entre las ideas políticas del filósofo de Königsberg y los presupuestos del republicanismo de Rousseau ni es fortuito ni cabe tampoco ocultarlo. El propio Kant confesó abiertamente que gracias al «Newton del mundo moral» pudo traspasar el círculo de sus intereses epistemológicos y abrir su pensamiento a las cuestiones político-sociales. Kant coincidía con el ginebrino en que la guerra además de constituir el principal freno de las necesarias reformas políticas de los Estados era un mal en sí mismo intolerable: la guerra era, en definitiva, el summum malum en cuanto «destructora de todo bien» (Kant, 1987, p. 95). Volvía a coincidir con Rousseau en que el establecimiento de una federación europea era una imposibilidad práctica en su tiempo. No era Rousseau, con todo, su única fuente de inspiración en estas materias y no faltaban tampoco los desacuerdos con el ginebrino, pues como afirma Gallie $(1980$, p. 46), «en su teoría internacional, Kant [...] debía menos a Rousseau de lo que él imaginaba y más a Vattel de lo que estaba dispuesto a admitir».

Hasta el siglo Xvili, la manera más frecuente de tratar filosóficamente el problema de la guerra y de la paz consistía en disertar sobre las condiciones necesarias para dirimir la licitud posible de una guerra, esto es, en elaborar una teoría acerca del iustum bellum, que persiguiera justificar la guerra como ultima ratio (pero ratio, finalmente). Así lo habían hecho, por ejemplo, en el XVI y en el XVII algunos neoescolásticos españoles. Los filósofos dieciochescos antes citados pretendieron, por su parte, establecer condiciones que imposibilitasen seguir considerando la guerra como una situación razonable (aunque en determinados casos pudieta ser tildada de racional) ${ }^{5}$. Es cierto que algunos autores, como Vattel, trataron tan

Esta distinción de origen kantiano ha sido. sistematizada recientemente por John Rawls (1995, pp. 79-85). Como es sabido, y dicho de la manera más simple, lo racional haría referencia a la búsqueda instrumental del propio interés y lo razonable a los téminos equitativos de la cooperación. 
sólo de humanizar las guerras desarrollando un ius belli o conjunto de normas de derecho internacional que estipularan ciertas limitaciones a las operaciones bélicas: desde los motivos para declaración de guerra (lo que la doctrina tradicional denominó ius ad bellum) hasta el tratamiento de los prisioneros (uno de los objetos del llamado ius in bello). Pero lo que singularizaría, en última instancia, dentro de este marco teórico, a autores como Saint-Pierre, Bentham o Kant sería la radicalización de sus objetivos: lo que se imponía era erradicar la violencia bélica, no domesticarla.

El jurista suizo y seguidor de Leibniz, Emmer de Vattel (1714-1767), está considerado como uno de los padres del derecho internacional moderno (cfr. Schmitt, 1979). En los límites teóricos del todavía denominado derecho de gentes se preocupó de la guerra y de las gestiones dirigidas al restablecimiento de la paz, cuestiones a las que dedicó un voluminoso libro escrito en plena Guerra de los Siete Años (cfr. Vattel, 1758, vol. II). Vattel no era ningún belicista y mostraba, por el contrario, una razonable actitud en favor de la paz. Sc encontraba, no obstante, dotado de una mentalidad realista que le llevaba a pensar que no se podía hacer otra cosa con la guerra que establecer normas para moderar o limitar su horror. Pensaba además que el cultivo de la paz era una obligación de los soberanos, ya que la guerra constituía un grave obstáculo para llevar adelante el desarrollo comercial y cultural de las naciones (ibídem, cap. I). Aunque sea preciso admitir que ninguna guerra puede preciarse de su licitud, sostenía que los Estados tenían en cualquier caso derecho a hacer la guerra por lo que consideran sus intereses. La guerra cra para Vattel aun hecho ineluctable y un instrumento de la vida política» (Gallie, 1980 , p. 46). Kant, que siempre mostró un claro rechazo a cualquier intento de juridificar la guerra, veía personificado este esfuerzo en Vattel. Kant tomó, no obstante, del suizo algunas de las restricciones o consejos prudenciales que detalló en los artículos preliminares de su proyecto de paz perpetua. Consideraba especialmente despreciable e insidioso que todavía se siguiera citando a Hugo Grocio, Samuel Pufendorf y, sobre todo, a Vattel (Kant, 1985, p. 23) para defender la bondad de las guerras estrictamente controladas. Pero desde su firme convicción de que «el derecho no puede ser decidido mediante la guerra» (Kant, 1985, p. 23), desconfió siempre de la fuerza y nunca de las virtudes de los instrumentos jurídicos acordados en común.

\section{Kant: paz sólo en la cosmópolis}

En los últimos años de su vida Kant abordó con gran entusiasmo la cuestión de la paz en conexión con el derecho y las relaciones internacionales. Aunque en ningún otro lugar como en La paz perpetua (1795) prestó mayor atención a este asunto, con anterioridad ya había subrayado un punto que aclara suficientemente sus intereses por la materia. Así, en el principio octavo de su opúsculo Ideas para una historia unwersal en clave cosmopolita de 1784, Kant señaló que la adecuada y satisfactoria articulación de una comunidad política depende de la regulación de las relaciones internacionales. Aquí Kant muestra especial interés en conceder 
al ciudadano un ámbito político donde pueda desenvolverse como un sujeto libre e igual, pero advirtiendo que tal objetivo no puede alcanzarse - en esto estriba la originalidad de su aportación- si no se adopta un punto de vista cosmopolita. Retomando explícitamente la idea de Saint-Pierre, considera que para la consecución de tal fín es preciso que los Estados ingresen, por muy costoso que sea, «en una confederación de pueblos, dentro de la cual aun el Estado más pequeño pudiera contar con que tanto su seguridad como su derecho no dependiera de su propio poderío o del propio dictamen jurídico, sino únicamente de esa confederación de pueblos, de un poder unificado y de la decisión conforme a leyes de la voluntad común» (Kant, 1987, p. 14).

En el verano de 1795 , cuando aún no había logrado sobreponerse a la impresión producida por la firma meses atrás, en abril, de la Paz de Basilea, acordada entre la revolucionaria República Francesa y la contrarrevolucionaria Monarquía Prusiana, Kant elaboró una propuesta práctica, con intención política -el mismo hecho de su publicación en ese momento puede considerarse un acto de significado político- e impregnada de sentido ético, que marcaría un hito en la historia del irenismo y del derecho internacional. Aquel tratado franco-prusiano había puesto de manifiesto la dificultad de alcanzar una paz que fuera más allá de un mero cese de hostilidades o de un armisticio sin la existencia de alguna garantía externa al interés o la buena voluntad transitoria de las partes. Las victorias militares eran las que de hecho dictaban los tratados de paz, que como tales no cran más que la imposición del derecho por el más fuerte.

$\mathrm{El}$ opúsculo kantiano ha de entenderse, según reza su subtítulo, como «un proyecto filosófico», donde proyecto no posee la acepción de boceto, modelo o propuesta, sino que tiene, según la terminología propia del criticismo, el sentido de una «idea necesaria» surgida de la razón y de la historia (cfr. Klenner, 1996, p. 155). De ahí que el proyecto esté dedicado a la indagación de los requisitos imprescindibles para fundamentar una paz perpetua $o$, usando la jerga kantiana, a la investigación de las «condiciones de posibilidad» de tal meta. Se trata de un breve folleto que resulta único entre las obras de Kant, por cuanto que fue escrito para un gran público, y aunque ciertamente el autor no estuviera dotado para la expresión popular, algunos apartados resultan sorprendentemente directos y concretos, además de polémicos. Si bien el contenido del escrito es, sin duda, serio, un cierto tono irónico resulta perceptible en su estructura, cerrada sobre sí misma, que adopta a propósito la factura enrevesada de un solemne protocolo diplomático, de un auténtico tratado de paz: sus dos apartados encierran, respectivamente, seis artículos preliminares y tres definitivos, a los que se añaden dos suplementos y dos apéndices e incluso un «artículo secreto». Ese articulado especifica los requisitos previos y las condiciones definitivas imprescindibles para alcanzar el objetivo buscado. La seriedad del contenido queda además resaltada por la licencia estilística empleada, cuyo artificio nos muestra a un Kant buen conocedor de los usos propios de ese pragmatismo incondicionado adoptado por la acción política en su quehacer cotidiano. Incluso se reserva un tono cáustico para identificar la «concepción ilustrada de la prudencia política», ese inmoral afán por «el continuo incremento del poder sin importar los medios», con la «astucia de la serpiente» (Kant, 1985, p. 6). 
Para Kant, como para tanto seres humanos antes y después de él, la guerra es un mal en sí mismo principalmente argumentaba--, porque en ninguna situación bélica pueden garantizarse los derechos más elementales de las personas, que se ven incluso incapacitadas para disfrutar de su libertad moral. Por eso, evitar que acaezcan las guerras o, dicho en positivo, instaurar un estado de paz (o construir un mundo en paz) se convierte en una meta práctica ineludible:

"Puede decirse que este establecimiento universal y duradero de la paz no constituye sólo una parte, sino la totalidad del fin final de la doctrina del derecho, dentro de los límites de la mera razón; porque el estado de paz es el único en el que están garantizados mediante leyes lo mío y lo tuyo, en un conjunto de hombres vecinos entre sí, por tanto, que eștán reunidos en una constitución» (Kant, 1989, pp. 195 y 196).

Esta meta, empero, no es nada accesible, porque el enfrentamiento entre los hombres hunde sus raíces en la propia naturaleza. La paz no es el estado natural, sino una conquista de la voluntad consciente del hombre, y debe, por tanto, ser instaurada (Kant, 1985, p. 14): pax est quaerenda. El estado de naturaleza kantiano es, a diferencia de Rousseau, «un estado de guerra en el que si bien las hostilidades pueden no haberse declarado, existe una constante amenaza» (ibídem, p. 14) o, dicho more hobbesiano, la situación entre los Estados no es otra que la de un potencial bellum omnium contra omnes. Pero a diferencia de Hobbes, tal situación no se da tan sólo en el ámbito político interno, sino también en las relaciones entre los distintos Estados. La analogía llega a ser completa, dado que «los pueblos, como Estados que son, pueden considerarse a modo de individuos en estado de naturaleza» (Kant, 1985, p. 21). Ante la mirada de cse paisaje desolador que ofrece el estado de naturaleza en que viven los pueblos, «la razón práctico-moral», como escribiria Kant en La metafisica de las costumbres, wormula en nosotros su veto irrevocable: no debe haber guerra; ni guerra entre tú y yo en el estado de naturaleza, ni guerra entre nosotros como Estados» (Kant, 1989, p. 195). Los Estados deben salir de la situación de guerra en virtud del mismo imperativo categórico que obliga a los individuos a asociarse al Estado y a los Estados a su vez a construir una unión de Estados. Si la solución anunciada por Hobbes para limitar el uso de la fuerza física era, en la política interna, la concesión del monopolio de la violencia a una sola instancia -el terrible I eviatán-, la propuesta kantiana pasa por la constitución de un estado jurídico cosmopolita que posibilite extender también a las relaciones internacionales la prohibición del recurso a la guerra. Del mismo modo como actúan los individuos en la sociedad interna, así pueden proceder los Estados en la sociedad internacional. Los mismos frenos que impiden que los hombres sigan luchando sin fin entre sí serán los que detendrán la lucha entre los Estados. Un estado de paz entre los Estados requerirá, por tanto, un «contrato social originario» entre los Estados.

Tras esta presentación general del diagnóstico del problema, así como del tratamiento propuesto por Kant para superarlo, vuelvo ahora a la estructura de la argumentación kantiana en su propio orden de exposición. Los artículos preliminares, formulados como prohibiciones, no planean de ninguna manera en las alturas de la especulación filosófica, sino que de modo muy directo van a los 
asuntos reales que hay que considerar si uno se adentra en el mundo de la diplomacia internacional. Por ello Kant examina con cierto pormenor los requisitos previos que harían posible la adopción de las medidas encaminadas a la consecución de una paz perpetua: la desaparición en los tratados de paz de toda reserva mental sobre futuras reivindicaciones, la prohibición de considerar a cualquier Estado susceptible de herencia o de transacción comercial, la abolición de los ejércitos permanentes, la no injerencia en los asuntos internos de los otros Estados y la recusación de ardides bélicos deshonrosos, tales como el asesinato, el envenenamiento o el espionaje. Tras estas interdicciones y providencias se encuentra sin duda la convicción - de impronta aristotélica- de que no es lícito separar moral y política, que Kant recibe de Rousseau. Así, la célebre sentencia emitida en el Emile - «Ceux qui voudront traiter séparément la politique et la morale n'entendront jamais rien à aucune de deux»- ilumina este pensamiento kantiano: «La verdadera política no puede dar un paso sin haber antes rendido pleitesía a la moral», cuyo sentido se ve completado casi a renglón seguido por esta apostilla: «toda política debe doblar su rodilla ante el derecho» (Kant, 1985, p. 60). La necesaria vinculación entre los distintos ámbitos de la razón práctica -la moral, el derecho y la política- queda garantizada, según Kant, con la ayuda del principio de publicidad, que en cierto sentido ejerce, como ha observado Habermas (1992, pp. 136-149), en la esfera política la misma función de canon crítico que el imperativo categórico desempeña en el ámbito moral, haciendo así las veces de principio de mediación entre política y moral. Ese principio reza como sigue: «son injustas todas las acciones que se refieren al derecho de otros hombres cuyos principios no soportan ser publicadosi (Kant, 1985, pp. 61 y 62) ${ }^{6}$.

Pasando ya al capítulo de los artículos definitivos de la paz perpetua, el primero estipula como un requisito esencial para alcanzar una paz estable y duradera el establecimiento de una constitución republicana. Kant contrapone Estado despótico y Estado republicano: éste, a diferencia de aquél, se organiza para la garantía de los derechos básicos en torno a la división de poderes, siempre bajo la égida de la soberanía popular: «El republicanismo es el principio político de la separación del poder ejecutivo (el Gobierno) del legislativo" (Kant, 1985, p. 18). Es la única forma constitucional que resulta verdaderamente de la idea de contrato social $y$, por ende, "la única perfectamente adecuada al derecho de los hombres» (ibidem, p. 38). Lo cual tiene aún mayor sentido si se considera que kel derecho de los hombres debe mantenerse como cosa sagrada por grande que sean los sacrificios del poder dominante» (ibidem, p. 60).

\footnotetext{
- En su origen histórico, el principio de publicidad venia a poner remedio a la proliferación de los arcana imperii, esto es, a los secretos políticos tan caros al absolutismo y a los modos diplomáticos. La publicidad se transforma así en un instrumento eficaz de control frente a la tradicional política de gabinete ejecutada por unas cuantas personas a puerta cerrada. Tal como a finales del siglo xvm Kant elevó a concepto, las propuestas y actuaciones que afectan a los derechos de los ciudadanos deberían someterse de modo general al control de publicidad, pues sólo el carácter público de las máximas subjetivas garantiza el respeto a la libertad de lodos y cada ono. El efecto práctico buscado por la aplicación de este principio sería evitar que todas aquellas cazones que no están permitidas hacer valer en público, esto es, que no admitan luz y taquígrafos, se empleen, empero, en ocultas negociaciones sobre asuntos de interés general.
} 
La idea de república no sólo es composible con la de democracia, al menos en su forma representativa ${ }^{7}$, sino que como ya advirtieron contemporáneos de Kant, son términos difícilmente separables. Sobre el término «tepublicanismo» Kant hace pivotar también la idea de una constitución política en donde el súbdito siempre sea a la vez ciudadano (Kant, 1985, p. 17). El ciudadano, se lee en La metafisica de las costumbres, wha de ser considerado en el Estado como miembro colegislador (no simplemente como medio, sino al mismo tiempo como fin en sí mismo) y que, por tanto, ha de dar su libre aprobación por medio de sus representantes» (Kant, 1989, p. 184; cfr. Kant, 1987, p. 95). Esta idea central de la filosofía política de Kant, que conforme a Maus (1992) le hace merecedor del calificativo de demócrata radical avant la lettre, significa, de acuerdo a la lectura de esta misma autora y también de Habermas, el pleno reconocimiento de la autonomía pública del individuo, que como tal sólo puede ser considerado súbdito, esto es, destinatario de las leyes de un Estado, si también es al mismo tiempo legislador, esto es, si participa activamente en el proceso de elaboración de las leyes (cfr. Kant, 1987, p. 95). El estatuto de ciudadanía es sinónimo de autonomía política. Esta noción de la facultad legislativa de todo ciudadano entronca directamente con el modo rousseauniano de afrontar la cuestión fundamental del derecho político, la cuestión de la legitimidad, esto es, icómo puede establecerse un Gobierno legítimo? El ginebrino formulaba, como es sabido, el problema al que da solución el contrato social (y, por ende, el acto de asociación y la propia institución estatal) del siguiente modo: «Encontrar una forma de asociación que defienda y proteja con toda la fuerza común a la persona y a los bienes de cada asociado y por la que, uniéndose cada cual a todos, no obedezca, sin embargo, más que a sí mismo y permanezca tan libre como antes» (Contrat social, $\mathrm{I}, \mathrm{p}$. 6). Ésa era precisamente la aspiración recogida en la noción de libertad jurídica definida por Kant como «la facultad de no obedecer a ninguna ley exterior más que a la que he podido dar mi asentimiento» (Kant, 1985, p. 16, nota 4).

Este primer articulo definitivo le sirve a Kant, entre otros objetivos, para marcar claramente las distancias con el abate de Saint-Pierre, amén de para señalar las insuficiencias del pacifismo meramente jurídico. En este artículo se perfila la intuición básica del denominado «pacifismo democrático» (Bobbio, 1992, p. 182), a saber: la condición (necesaria) de la paz es una constitución republicana $o$, dicho con otras palabras, la democracia, si nos atrevemos a traducir el término kantiano de modo infiel en cuanto a su literalidad, pero completamente fiel respecto a su sentido político actual. La democracia se presenta entonces como el medio más adecuado, tanto para la regulación de conflictos como para su prevención, en orden a lograr una paz firme y duradera.

Según el segundo artículo definitivo para la paz perpetua, «el derecho de gentes debe fundarse en una federación de Estados libres» (Kant, 1985, p. 16). De este

\footnotetext{
${ }^{7}$ Kant considera que la democracia en cuanto forma de Estado se caracteriza porque la soberanta la poseen atodos los que forman la sociedad civil conjuntamente» (Kant, 1985, p. 18), y por tanto es, en su sentido etimologico, un despotismo, pues no existe distinción entre el sujeto del poder legislativo y del ejecutivo. La democracia sólo resulta compatible con el republicanismo si se profundiza en el carácter representativo y se articula mediante la división de poderes.
} 
modo se muestra que el objetivo del opúsculo no es, en realidad, configurar un Estado mundial, sino tan sólo establecer una sociedad cooperativa de naciones carente en principio de un centro de poder unificado. La diversidad estatal o, si se prefiere, la diversidad de naciones, es un presupuesto irrebasable de la concepción kantiana del derecho internacional. Kant quiere eludir cualquier senda que pudiera conducir a la uniformación de los pueblos y a la anulación de las diferencias culturales, pues con-ello tan sólo se alcanzaría la tan denostada paz de los cementerios.

Enmendando la plana a Hobbes, Rousseau sostenia que «no hay guerra entre los hombres, sólo hay guerra entre los Estados» (Rousseau, 1982, p. 53). Sin embargo, se mostró indeciso en este punto y no llcgó a aclarar cómo superar el «estado de naturaleza» interestatal. Por su parte, Kant, alejándose de nuevo de Rousseau, señaló con hincapié que la paz general y perpetua era una creación contractual, fruto de un foedum pacificum:

*Tiene que existir una federación de tipo especial a la que se puede llamar la federación de la paz (foedas pacificum), que se distinguiría del tratado de paz cn que éste buscaría meramente el acabar con una guerra, pero aquélla buscaría acabar para siempre con todas las guerras" (Kant, 1985, p. 24).

Kant, ciertamente, consideraba que habia que ir a las raíces del problema, pues, como diría en nuestro siglo Ernst Bloch (1979, II, pp. 482 y 483), «el pacifísmo no consiste en terminar a todo precio con las guerras, sino impedir en sus causas guerras futuras». Según la filosofía política kantiana, otra vez diferenciándose de Hobbes, el Estado estructurado bajo el imperio de la ley como Estado de derecho es incapaz de garantizar la paz interna si no se inscribe en un doble marco jurídico: por un lado, en un derecho de gentes fundado en una federación de Estados libres que, sin embargo, no puede ser un estado de pueblos, $y$, por otro lado, en un derccho de los ciudadanos del mundo.

La aportación más original del texto kantiano a la teoría del derecho en general es la configuración tripartita del orden jurídico mediante la inclusión junto al derecho público interno y externo - que era la división tradicional- de una nueva especie de derecho que denomina ius cosmopoliticum. De los tres artículos definitivos del imaginario tratado de paz perpetua, el primero, según el cual la constitución de todo Estado debe ser republicana, incumbe al derecho público interno; el segundo, por el cual el derecho internacional debe basarse en una federación de Estados libres, pertenece al derecho público externo; el tercer artículo, sin embargo, corresponde a una especie inédita. Reza así: «El derecho cosmopolita debe limitarse a las condiciones de una universal hospitalidad" (Kant, 1985, p. 27). Kant señala de este modo que además de las relaciones entre el Estado y sus ciudadanos y las del Estado y los otros Estados se deben tomar en consideración también las relaciones entre todo Estado y los ciudadanos de los otros Estados:

«En esta relación de reciprocidad entre el derecho de visita del ciudadano extranjero y el deber de hospitalidad del Estado visitado, Kant había prefigurado originariamente el derecho de todo hombre de ser ciudadano no sólo del propio cstado, sino del mundo entero, 
y se habia representado la tierra entera como una potencial ciudad del mundo, precisamente como una cosmópolis» (Bobbio, 1991, p. 182).

Este derecho cosmopolita le servía a Kant para cerrar y culminar el sistema general del derecho: ponía las bases de un nuevo orden del mundo y preparaba asi la realización de la paz perpetua. Es aquí donde aparece como una auténtica necesidad para la instauración de la paz la constitución de un derecho cosmopolita que actúe como principio regulador del espacio internacional. Ese «derecho cosmopolita», noción que enlaza con la idea estoica de una civitas maxima, lo entendía Kant como «la posible asociación de todos los pueblos en orden a ciertas leyes generales de su posible comercio», en la inteligencia de que «comercio» tiene aquí el sentido amplio de interacción. Poco después, en 1797, al publicar La Metafisica de las costumbres, completố esa definición: "Este derecho, en tanto que conduce a la posible unión de todos los pueblos con el propósito de establecer ciertas leyes universales para su posible comercio, puede llamarse el derecho cosmopolita (ius cosmopoliticum) (Kant, 1989, p. 192).

Según Truyol y Serra (1979), la aportación más decisiva de Kant a la teoría del derecho internacional fue, sin duda, la idea de que la precariedad de este ordenamiento jurídico sólo puede ser superada por la vía de la creación de una organización internacional. Kant vinculó sistemáticamente la posibilidad de la paz entre los Estados a la instauración de una entidad de alcance universal como paso previo a la constitución de un Estado mundial. Por ello, mientras no se llegue a instaurar dicho Estado el derecho de gentes, que estrictamente hablando debería denominarse «derecho de los Estados» o ius publicum civitatum (Kant, 1989, p. 181), no pasa de ser un sustitutivo provisional de escasa eficacia. Hay quienes, empero, aprueban este paso lento y prudente: «No obstante, y aunque propugna una única república universal, Kant posee, pese a todo su rigorismo moral, suficiente buen sentido para conformarse con un sucedáneo entre los actuales Estados depredadores: la sociedad de naciones» (Bloch, 1979, II, p. 482).

Rousseau ponía incluso en duda que fuera factible una unión de los Estados europeos y, mucho más, una asociación mundial de Estados. Lo dudaba por su conocimiento de la política internacional, pero no porque la considerase en sí una idea descabellada. Así, en referencia al proyecto del abate Saint-Pierre, sostuvo que «si a pesar de todo este proyecto continúa sin ponerse en práctica, no es porque sea una quimera, es porque los hombres son unos insensatos y porque una de las clases de locura es estar cuerdo en medio de los locos» (Rousseau, 1982, p. 33). Kant, sin embargo, sí se hizo cuestión de la posibilidad de instaurar un Estado universal y por ello investigó las condiciones de posibilidad del mismo. No se le ocultaba que las condiciones requeridas no se daban en la situación política, tanto interna como externa, de los Estados de su tiempo, de modo que, al presentar un catálogo estricto de condiciones tan sólo marcaba un horizonte ideal al que la humanidad debía tender. Eso no significa que fuese un pensamiento quimérico o propio de un visionario. Con el tiempo ese ideal ha sido reconocido como una adquisición decisiva en el desarrollo de las relaciones internacionales y ha desempeñado incluso un destacado papel como factor dinamizador de su desarrollo histórico. No más eficacia ni tampoco menos esperaba Kant de su escrito. 
La idea kantiana de una paz perpetua lograda o, mejor dicho, instaurada, a través de un Estado universal, cosmopolita, conticne las notas propias de una idea regulativa. Como es sabido, para Kant una «idea regulativa» tiene la virtud de permitir actuar como si ciertas metas fueran posibles. Decir que la paz perpetua es una idea regulativa significa que podemos y, es más, hemos de actuar como si fuera posible su instauración, tomándola como orientación para nuestras acciones y como criterio para juzgar situaciones reales, esto es, como canon para la crítica. La idea misma de la paz perpetua abre un «horizonte de esperanza» y señala una tarea para la humanidad. Al respecto Gallie ha señalado que «el proyecto de Kant difería de todos los demás que lo habían precedido en que combinaba una demanda moral urgente de "acciốn inmediata" con un sagaz reconocimiento político de la larga cuesta arriba que esa acción exigiría (Gallie, 1980, pp. 52 y 53). La noción de paz perpetua puede entenderse, por consiguiente, como un proyecto ético-político. El esfuerzo político por acercarse a ella constituye como tal una tarea infinita, una meta a la que cabe irse aproximando de manera laboriosa, que requiere, por tanto, una enorme energía moral. Es más, Kant sostenía que debemos trabajar por la paz aunque no sepamos «si la paz perpetua es algo real o un sinsentido", es decir, «debemos obrar sobre su fundamento como si fuera una cosa posible» (Kant, 1989, p. 195). En este mismo sentido, en las últimas palabras de su opúsculo de 1795 señalaba:

«Si existe un derecho y al mismo tiempo una esperanza fundada de que hagamos realidad el estado de un derecho público, aunque sólo sea en una aproximación que pueda progresar hacia el infinito, la paz perpetua, que se deriva de los hasta ahora mal llamados tratados de paz (en realidad, armisticios), no es una idea vacta sino una tarea que, resolviéndose poco a poco, se acerca permanentemente a su fin (porque es de esperar que los tiempos en que se producen iguales progresos sean cada vez más cortos) (Kant, 1985, p. 69, cursiva de JCVA).

La apuesta por la paz no es en sí, por tanto, una meta racional, sino tan sólo un objetivo razonable que alcanza plausibilidad en el marco de una determinada filosofía de la historia: la paz aparece en última instancia asegurada en el «plan secreto de la naturaleza» (cfr. Kant, 1995, pp. 31-41). Como es sabido, en la filosofía de la historia pergeñada por Kant se incluye la noción de progreso, mas un progreso asintótico, esto es, de un decurso cuyo desenlace se ve transferido al horizonte de un remoto futuro. No le falta, pues, razón a Truyol y Serra:

«La filosofía del derecho de Kant desemboca en una filosofía de la historia: el Estado mundial, Estado mundial de Derecho en cuanto república mundial, condición de la paz perpetua, es no sólo el fin de la doctrina del derecho, sino el fín del devenir histórico de la humanidad» (Truyol y Serra, 1979, p. 61).

Puede parecer, sin duda, un rasgo de ingenuidad la confianza depositada por Kant en el «secreto designio de la naturaleza» y ésa es una impresión subjetiva que perdura incluso interpretando, de modo caritativo, tal concepto como destino o como providencia - una opción que, por otro lado, alentaría las dudas sobre 
el nivel de secularización de la ilustración kantiana-. Pero de ahí no cabe colegir que el filósofo de Königsberg fuera un iluso sin sentido alguno de la realidad. Proponía una asociación por la paz primero entre algunas naciones favorables a ella y sólo después entre todas las naciones. No se hacía muchas ilusiones al respecto, y en una muestra de cabal percepción de la Realpolitik mantenía que los Estados se verían obligados a aceptar el nuevo orden internacional forzados por las destructivas y costosas consecuencias de guerras cada vez más violentas y no tanto por sus propios deseos. Esta observación pesimista o, si se prefiere, realista, se ha visto confirmada en el presente siglo: el nacimiento de las dos organizaciones internacionales de mayor alcance coinciden con los finales de sendas guerras mundiales.

Como conclusión de este apartado, cabe concordar en parte con Gallie (1980, p. 48) en que «Kant no era un pacifista, sino un apasionado legalizador». Ciertamente mostraba una inconfundible actitud legalista al considerar que el reconocimiento de la paz perpetua entre las naciones era necesario como primer paso en cualquier progreso seguro hacia un orden jurídico internacional. Hasta aquí cahría entonces adjudicarle sin más la etiqueta de «irenista jurídico», como hace Bobbio, si no fuera porque otorga un relevante lugar a la política al hacer depender de la democratización interna de los estados el establecimiento de una organización cosmopolita garante de la paz.

\section{John Rawls y el derecho de gentes: una de Kant y otra de arena}

A John Rawls se debe, sin ninguna duda, la expresión paradigmática de la teoría liberal contemporánea. Es más, tanto su Teoría de la justicia de 1971 como El liberalismo político de 1993 se han convertido en el punto de referencia de cualquier discusión sobre la teoría normativa de las sociedades democráticas. No es ésta, sin embargo, la razón que conduce a prestar aquí atención a su obra, sino, en primer lugar, el hecho de que Rawls sea uno de los principales protagonistas de la rehabilitación de la filosofía práctica kantiana en los últimos años (cfr. Thiebaut, 1984). Esta veta kantiana persiste a pesar de que en su último libro haya marcado las distancias que separan el constructivismo moral de Kant del constructivismo político de la justicia como equidad y haya calificado además a aquel modelo como doctrina comprehensiva (Rawls, 1996, pp. 130-132). A la postre, Rawls sigue reconociendo su considerable deuda con respecto al concepto kantiano de razón práctica.

En ninguna de las dos principales obras de Rawls es posible hallar un desarrollo por extenso de los problemas de la justicia relativos a las relaciones entre los diferentes pueblos de la ticrra. Tan sólo en un pequeño apartado de su primera obra, concretamente en la sección 58 , Rawls realiza una breve aproximación a la cuestión de cómo extender a la esfera del derecho internacional una concepción de la justicia pensada para el ámbito doméstico o local. En esa sección, dedicada en realidad a justificar la objeción de conciencia a participar en ciertos actos de 
guerra, presupone la posibilidad de trasladar los mismos principios de la justicia como imparcialidad a la esfera internacional, apuntando, por tanto, el posible empleo de los mismos parámetros de los que se sirve para construir la justicia en el interior de los Estados. Así, en un remedo de la «posición original», los representantes de las diferentes naciones, sujetos - como los individuos privadosa las restricciones del velo de ignorancia, se reunirían para deliberar sobre la estructura básica de una sociedad mundial bien ordenada. También en su segundo opus magnum, El liberalismo político, Rawls se abstuvo de abordar la cuestión del derecho internacional en espera de hacerlo más detenidamente en un artículo ad hoc. Anunciaba tan sólo que habría que modificar algunos puntos de una teoría pensada para ser aplicada en sociedades cerradas (1996, p. 42). Ya en este texto concibe el derecho de gentes como «los conceptos y principios que se aplican al derecho internacional y a las relaciones entre las sociedades políticas» (1996, pp. 51 y 280), si bien sigue remitiéndose al parágrafo 58 de su Teoría de la justicia.

En rThe Law of People», un largo artículo aparecido en 1993 poco después de El liberalismo político, Rawls amplía por fin su perspectiva teórica y el entramado conceptual se hace ahora mucho más complejo. En realidad, se observa una nueva formulación, la tercera, de la teoría rawlsiana de la justicia. Se trata esta vez de extender su noción del liberalismo político al derecho de gentes entendido como «una concepción política del derecho y la justicia aplicable a los principios y normas del derecho y la práctica internacionales» $(1997$, p. 5). Según Rawls, el derecho de gentes incluye, entre otros puntos que no son de interés aquí, una extensa referencia al papel de los derechos humanos en el ámbito de las relaciones internacionales, de tal manera que esos derechos reemplazan a cualquiera de las anteriores concepciones de la justicia - como la equidad o la imparcialidad-y ocupan ahora una posición central, aunque sea a base, dicho sea de paso, de minimizar sus exigencias normativas.

El derecho de gentes, en la versión de Rawls, del mismo modo que su concepción del liberalismo político, no constituye una doctrina comprehensiva (de carácter totalizante o globalizador), ni tampoco puede basarse en una determinada concepción religiosa, filosófica o moral. Es, por el contrario, una teoría puramente política compatible con la pluralidad de doctrinas existentes en el mundo moderno. Hay comunidades culturales y nacionales que representan valores tan radicalmente diferentes que no parece posible construir en el mundo considerado globalmente un orden político respaldado por la fuerza del derecho cuya estructura básica fuese aceptable para todos ${ }^{8}$.

El punto de arranque de la concepción de la sociedad internacional desarrollada por Rawls es la articulación de un modelo lo más abierto posible de manera que en ella puedan tener cabida, en virtud del principio liberal de tolerancia, también sociedades no liberales. La cuestión crucial aquí tendría que versar sobre los límites de la tolerancia en las relaciones cntre los Estados: ¿por dónde deben ser trazados esos límites? Rawls afronta la resolución de esta cuestión estableciendo una tipología de las distintas sociedades. El ámbito de aplicación del principio de tolerancia

Esta convicción rawlsiana es compartida por otros muchos autores como, por ejemplo, Nagel (1996, pp. 171-180). 
abarca tanto a las sociedades liberales como a las sociedades no liberales o jerárquicas con tal que sean «sociedades bien ordenadas». Por tal se entiende toda sociedad que sea epacífica y no expansionista, con un sistema legal que satisface, a los ojos de su propia ciudadanía, ciertas condiciones de legitimidad y, en consecuencia, que respeta los derechos humanos básicos» (Rawls, 1997, p. 2). Las «sociedades no bien ordenadas" (para entenderse, los regímenes tiránicos o dictatoriales) que no cumplen estos requisitos mínimos son considerados regímenes proscritos o, lo que es lo mismo, quedan excluidas de los beneficios de la sociedad intcrnacional. De este modo, aunque el principio liberal de tolerancia trasciende las lindes propias de las sociedades liberales, su aplicación encuentra un límite infranqueable en el respeto de las condiciones constitutivas de una "sociedad bien ordenada". El elevado grado de abstracción en el que se mueve el texto rawlsiano permite, no obstante, tanto una lectura estricta como otra más flexible de estos limites normativos (cfr. Espósito y Peñas, 1995).

Los derechos humanos básicos que el ordenamiento jurídico de toda sociedad bien ordenada debe proteger coinciden esencialmente con los que la doctrina denomina comúnmente derechos civiles, a saber: «el derecho a la vida y a la seguridad, a la propiedad privada y a los elementos del Estado de derecho y, del mismo modo, el derecho a cierta libertad de conciencia, a la libertad de asociación y a la emigración» (Rawls, 1997, pp. 25-26). Entre estos derechos no se encuentran los derechos de participación política, pues su no observancia por una sociedad no determina de modo automático su inclusión entre los regímenes proscritos: tan sólo se trata de un rasgo diferenciador de los regímenes liberales. En esta relativa laxitud cstribaría una de las particularidades del ensayo rawlsiano acerca de la concepción liberal del derecho de gentes: «mientras una sociedad respete los derechos humanos básicos no necesita ser liberal. Esto también muestra el papel de los derechos humanos como parte de un derecho de gentes razonable» (Rawls, 1997, p. 6). I as sociedades liberales y las sociedades jerárquicas pueden, pues, reconocer un mismo derecho de gentes sin tener que compartir las mismas razones de fondo. En este sentido el derecho de gentes no presupone una doctrina comprehensiva, esto es, no constituye una doctrina metafísica, sino política. Esto no empece para que, por ejemplo, en las sociedades jerárquicas una determinada confesión religiosa pueda alcanzar el estatuto de religión de Estado, pero eso sí, resulta imprescindible para que puedan considerarse como sociedades bien ordenadas que nadie sea perseguido por sus creencias (cfr. Rawls, 1997, p. 21).

Aunque para Rawls los derechos humanos básicos son «políticamente neutrales» (Rawls, 1997, p. 26), de tal manera que no predeterminan una estructura de carácter democrático, cumplen empero tres importantes funciones en el orden político: aportan legitimidad a los regímenes políticos, excluyen la posibilidad de una intervención exterior justificada, y establecen un slímite moral al pluralismo entre los pueblos» (Rawls, 1997, p. 28). Desempcñan además, por si fuera poco, la importante misión de especificar los límites de la soberania estatal interna y de determinar el límite exterior del derecho nacional admisible (ibidem).

La versión rawlsiana del derecho de gentes proporciona un principio de justicia que pretende servir de norte en las relaciones entre las diferentes naciones. $Y$ 
aunque dicho principio se encuentra matizado por el principio liberal de tolerancia, aporta criterios nítidos para diferenciar en la escena internacional los estados «admisibles» de los Estados proscritos: junto con la prohibición del expansionismo militar, «los derechos humanos determinan los límites de la tolerancia en una razonable sociedad do naciones" (Rawls, 1997, p. 33). El reconocimicnto y garantía de esos derechos ses una de las condiciones impuestas a cualquier régimen político para ser admitido como miembro de pleno derecho en una justa sociedad política de naciones» (Rawls, 1997, p. 33). Es más, junto con la defensa de la sociedad internacional, la protección en casos graves de los derechos humanos de «personas inocentes" sería el único motivo legítimo para una intervención armada contra regímenes proscritos (cfr. Rawls, 1997, p. 29). De este modo, Rawls toma partido en esa polémica todavía en curso accrca de la contraposición entre el principio de no injerencia y un presunto derecho de intervención bélica humanitaria (cfr. Walzer, 1995; Ruiz Miguel, 1996; Remiro Brotóns, 1996, pp. 30-43).

El principio de no injerencia, ya clásico en el derecho internacional, proclama la potestad de todo Estado a escoger su propio sistema politico, económico, social y cultural, sin intromisión de ninguna clase por parte de otro Estado. Por su parte, el denominado derecho de intervención autorizaría a los Estados a intervenir en los asuntos de la jurisdicción interna de otros Estados cuando se dieran circunstancias de excepcional gravedad, como v. gr., la violaciónt persistente de normas compartidas por la comunidad internacional (tales como los derechos humanos). Ante el riesgo de que el uso irrestricto de ese derecho de intervención degenere en ahusos, amén de otros motivos no siempre confesables, el vigente derecho internacional no lo reconoce, y de hecho, el capítulo VII de la Carta de Naciones Unidas sólo faculta al Consejo de Seguridad a emprender acciones militares en casos de grave amenaza a la paz y seguridad internacional. En favor de esta regla de no intervención cabe aducir que supone un cierto reconocimiento del derecho a la diferencia y que, por el contrario, en esa tendencia actual a generalizar el derccho de injerencia parece observarse un cierto rebrote de eurocentrismo en nombre de un integrismo democrático que confundiría lo occidental con lo universal ${ }^{9}$. En cualquier caso, ningún Estado está autorizado a imponer su propia concepción de la legitimidad política sobre el resto del mundo a menos que persiga constituirse en imperio mundial. Diferente scría si una entidad o asociación de alcance mundial y democráticamente configurada tuviera competencia reconocida para ello, pero sobre este asunto Rawls no nos dice mucho. Tan sólo, siguiendo explícitamente a Kant (1985, p. 40), rechaza que un Estado mundial sea el mejor garante de la paz y en su lugar propone algunas formas de asociación cooperativa (Rawls, 1997, p. 14).

En cuanto al estatuto normativo del derecho de gentes en su versión rawlsiana, debe señalarse que no coincide ni cabe identificarlo con el derecho internacional positivo. Tampoco los derechos humanos pensados para el ámbito de aplicación

${ }^{9}$ En pro de la preeminencia del principio de no intervención cabe también alegar que epone en mano de los pueblos la responsabilidad de su propio destino y entre sujetos estatales tienc un sentido igualador, democratizador. El carácter progresista de la no intervención ha de presumirse; el de la injerencia humanitaria ha de probarse caso por casos (Remiro Brotóns, 1996, p. 42). 
de ese derecho de gentes deben ser confundidos con los derechos fundamentales positivizados en las constituciones. El derecho de gentes se concibe, más bien, como una familia de «conceptos y principios por referencia a los cuales» el derecho internacional positivo «debe ser juzgado» (Rawls, 1997, p. 12). En realidad, aunque Rawls no lo exprese así, se presupone una relación de subordinación normativa del derecho internacional con respecto al derecho de gentes, que es, como cabe recordar, la misma clase de relación que según los defensores del derecho racional mantenía o debería mantener el ius gentium con respecto al derecho internacional propiamente dicho. Una rehabilitación de este esquema básico del derecho natural racionalista - no de sus fundamentos metafísicos- más explícita no se ha visto, a decir verdad, en los últimos años: bajo el ropaje de una teoría de la justicia parece revivir una vez más el viejo Derecho natural, resurgiendo con toda su escueta desnudez (aunque desprovisto de su antigua grandeza y ascendencia) como un fantasma de entre los muertos. En todo caso parece hoy extraño que para construir una teoría normativa de las relaciones internacionales se tenga uno que remitir al clásico concepto de ius gentium con todas las connotaciones que se le han adherido a lo largo de la historia.

Para los representantes de la neoescolástica española, y en particular para Francisco de Vitoria, el ius gentium tenía ya una doble dimensión: se refería tanto al derecho universal de la humanidad (a la manera romana) como al derecho de los pueblos organizados en comunidades políticas independientes en sus relaciones reciprocas (ius gentium intra se). Desde las formulaciones de la Escuela de Salamanca (cfr. Pérez Luño, 1992, pp. 77-119), en la base de la doctrina del derecho internacional se encuentra una concepción universalista: el derecho de gentes se presenta como un derecho común al género humano en su conjunto ${ }^{10}$. Es importante señalar este punto, porque luego quedaría bastante aminorado o desvirtuado: con el auge de la cxpansión europea en el mundo durante el siglo xIX el derecho internacional adoptaría un sesgo marcadamente eurocêntrico, convirtiéndose en una prolongación del «derecho público europeo», como há indicado inteligentemente Carl Schmitt (1979). En el concepto kantiano de itus cosmopoliticum se conservan, empero, esas dos dimensiones universalistas del ius gentium clásico, que como ha podido observarse también están presentes en Rawls.

El proyecto kantiano de paz perpetua incluía, recuérdese, dos aspectos diferenciados que, utilizando una terminología propia del derecho constitucional, cabría denominar constitución dogmática y constitución orgánica del sistema político mundial. La sección dogmática se referiría a los presupuestos normativos de indole moral y política. Ahí se encontrarían la garantía de los derechos humanos y el sistema de representación política. La constitución orgánica, por su parte, haría referencia a la estructura organizativa del orden cosmopolita, de la que, por cierto, tan sólo se anuncian algunas notas. Aunque el texto de Rawls no aporta tampoco mucho a este segundo aspecto, sí logra clarificar el contenido de la parte dogmática

Hi ius gentium tenia, desde la Edad Media (como puso de manifiesto el gran historiador del derecho Otto von Gierke, 1995), el sentido de un derecho unánimemente reconocido por todos los pueblos y, a la vez, se consideraba como la suma de las consecuencias del derecho natural. Era inmutable e inviolable como el derecho natural e igualmente carecía de carácter positivo. 
al atribuir a los derechos humanos el carácter de minimun moral exigible para acceder con plenos derechos a la comunidad internacional. No debe, sin embargo, pasarse por alto que mediante esta caracterización se corre el riesgo, nada remoto, de acabar interpretando exclusivamente las relaciones internacionales en términos morales. Aunque es cierto que Rawls deja abierta la cuestión de la justificación última de los derechos humanos para intentar que sean aceptados con independencia de las convicciones que cada cual sustente sobre el sentido del mundo y de la vida (su fundamentación pretende ser política, no metafísica), cabe sospechar que, como en el caso de su teoría de la justicia, se trate sólo de una explicitación de las intuiciones básicas incardinadas en las instituciones políticas de una sociedad liberal y occidental ${ }^{11}$. Es conocido que Rawls ha atemperando últimamente el marcado carácter universalista de sus inicios. Ahora sostiene que los principios de la justicia son válidos sólo a la luz de nuestra conciencia moral y política, esto es, de «las ideas intuitivas básicas que están arraigadas en las instituciones políticas de un régimen constitucional democrático y en las tradiciones públicas de su interpretación» (Rawls, 1985, p. 225). En tal caso, no le faltaría razón a Richard Rorty cuando enfatiza que los derechos humanos, como la propia democracia liberal, pueden recibir una articulación filosófica, pero su fundamentación filosófica, como tal, siempre resultará un fracaso ${ }^{12}$.

\section{Habermas: un paso más alla de Kant}

En 1995, con ocasión del segundo centenario de la aparición del texto de $L a$ paz perpetua, Habermas publicó un artículo en donde, además de rendir cumplido homenaje al sabio de Königsberg, presenta una lectura del famoso panfleto desde el horizonte de experiencias de nuestro tiempo. No pretende realizar, por tanto, un puro ejercicio de arqueología de las ideas: lo que le mueve es un interés práctico, como casi siempre, por reformular el ideal kantiano a la luz del actual estado de cosas en el mundo. Esa "reformulación" habcrmasiana sc orienta en su vertiente más propositiva hacia la transformación de las Naciones Unidas en una especie de Estado mundial y la modificación del derecho internacional vigente en clave más cosmopolita: en ambos sentidos Habermas da un paso más allá en la senda

"Stéphane Chauvier (1996) ha puesto de manifiesto que el proyecto rawlsiano adolece de un «déficit culturalista» que, a pesar de sus reiteradas protestas, le impide superar la frecuente acusación de curocentrismo. Espósito y Peñas (1995, p. 233) han señalado, por su parte, que una interpretación maximalista plausible de la tipología de sociedades establecida por Rawls seria que alos poderosos describirian, designarian y determinarian cuáles son las sociedades bien ordenadas y cuáles now, pudiendo así extraer interesadas consecuencias intervencionistas y sancionadoras.

12 «No se puede esperar más de la filosofía que una recopilación de nuestros supuestos intuitivos más influyentes culturalmente. Este resumen se confecciona formulando una generalización de las concepciones intuitivas con la ayuda de principios no polémicos. Esta generalización no trata tanto de fundar nuestras concepciones intuitivas como de resumirlas (Rorty, 1994, p. 106). El propio Rorty no se opone al cosmopolitismo, pero considera que no se avanza en esa dirccción por la vía del universalismo abstracto de corte kantiano, sino por el camino emotivo forjado por la educacion sentimental, en donde, como es sabido, la literatura juega un papel crucial. 
acotada doscientos años atrás. El avance se sitúa ahora, a diferencia de Rawls, en los aspectos organizativos: el pensador alemán pone el acento en lo que antes denominé «constitución orgánica» del orden internacional, aunque sin perder nunca de vista los aspectos normativos con implicaciones de carácter moral.

Habermas no puede menos que celebrar la idea kantiana de establecer junto al derecho estatal y al imperfecto derecho internacional un nuevo orden jurídico, un derecho de carácter cosmopolita. Mas ese reconocimiento no le impide señalar dos cuestiones que nos separan sin remedio del filósofo de Königsberg: por un lado, las experiencias históricas, que lógicamente son diferentes, y por otro, el uso del lenguaje característico del iusnaturalismo racionalista, cuyos presupuestos metafísicos ya no pueden aceptarse sin más.

El primer escollo que Habermas encuentra en el escrito kantiano es de tipo conceptual y se refiere a las características propias del preconizado derecho cosmopolita en relación con las del clásico derecho internacional (Habermas, 1997, p. 63). Dado que de su resolución depende el estatuto jurídico de la organización internacional que se desee fundar, no resulta una cuestión baladí. El rasgo distintivo entre ambos tipos de ordenamientos jurídicos sería la presencia de un órgano colegiado supranacional, al que Kant (1989, p. 191) ya denominó congreso permanente de Estados. Y es precisamente en este punto de la construcción kantiana donde Habermas advierte una contradicción, pues después de haber comparado la situación en la que se hallan entre sí los Estados con el estado de naturaleza previo al contrato originario, Kant deja el asunto curiosamente a modias: ante tal situación lo que se impone, según Habermas, no son los débiles lazos de una «federación continuamente libre», sino un poder vinculante, una autoridad coercitiva, capaz de imponer decisiones y garantizar la paz.

Es cierto que Kant habia señalado que una asociación o federación de Estados libres, en la que los Estados miembros mantienen intacta su soberanía e independencia, es tan sólo el objetivo próximo. Esta primera meta es, en verdad, un sucedáneo - inspirado por una percepción bastante realista de la historia- de una aspiración máxima, que no es otra que la constitución de una república mundial (Kant, 1985, pp. 25 y 26), pero lo cierto es que Kant no llega a perfilar en absoluto los rasgos constitutivos de la misma. Habermas aprecia, con todo, el valor de su propuesta, pues a pesar de la debilidad de los vínculos que establece esa asociación, son, con diferencia, lazos mucho más estrechos que los generados por el derecho internacional hasta entonces existente. $Y$ la idea misma de un congreso permanente de Estados supone también un adelanto: la doctrina tradicional del ius gentium nunca previó ni preconizó una institución semejante. Por eso cabe interpretar la indicación kantiana de no establecer más que una asociación de Estados libres como una prudente cautela, dado que en ese momento histórico ni eran comunes los Estados democráticos ni la soberanía estatal cabía entenderla de otra manera que como independencia (Habermas, 1997, p. 65). Una república mundial podia evocar la ominosa imagen de una monarquía universal (ibidem, p. 66).

Salvada ya la coherencia de Kant con sus propias experiencias históricas, lo que se requiere ahora es el esfuerzo de adecuar sus intuiciones básicas a la situación histórica de nuestro presente. El primer dato que habría que constatar sería la 
significativa merma de soberanía real padecida por la mayoría de los Estados contemporáncos, no tanto por propia voluntad de los más interesados, es decir, por quienes ostentan el poder en cada Estado, sino fundamentalmente a causa de procesos que ellos mismos ni han impulsado ni pueden controlar. Según el filósofo francfortiano, con la globalización de los intercambios cconómicos (integración de los mercados, flujos financieros, comercio mundial, etc.), de las comunicaciones y de las relacioncs políticas, el panorama internacional se ha transformado estructuralmente de manera tal que no sólo se cuestiona la noción tradicional de soberania, sino también aquel otro presupuesto esencial del derecho internacional clásico como era la tajante separación entre los asuntos propios de la política interior de los Estados y las cuestiones de politica exterior (cfr. Habermas, 1997, p. 68). Los doscientos años transcurridos no han agotado el ideal kantiano, pero sí han puesto de manifiesto la urgente necesidad de actualizarlo: sobre todo en lo que se refiere a la configuración de una organización internacional que ya no puede seguir siendo tan respetuosa con una autonomía estatal reducida a una mera expresión simbólica. Para vincular a los diferentes Gobiernos hace falta institucionalizar una suerte de derecho cosmopolita. Pero es más, no se trata tan sólo de obedecer los imperativos epocales, sino que hay razones normativas de peso para el establecimiento de un Estado mundial que garantice una ciudadanía única a todos los habitantes del planeta: sería la consecuencia lógica tanto de la noción de democracia como de la de los derechos humanos. La autonomía pública del ciudadano, esto es, su pleno reconocimiento como sujeto político responsable, no puede quedar mediatizada por la soberanía de los Estados (Habermas, 1997, pp. 73 y 74). Habermas concibe la federación cosmopolita menos como una asociación de Estados y más como una asociación de ciudadanos. En cualquier caso y a diferencia de Kant, Habermas no hace depender, en última instancia, su posibilidad ni su éxito de una problemática - es lo menos que se puede decir- filosofía de la historia, sino de la dinámica propia del juego político.

El establecimiento primero de la Sociedad de Naciones y posteriormente de la Organización de las Naciones Unidas marcan dos hitos históricos en la institucionalización de los intercambios mundiales: contribuyeron a extender el ámbito de aplicación de las normas del derecho internacional virtualmente a toda la humanidad. Las Naciones Unidas, en particular, han adoptado desde su nacimiento la forma de un foro permanente de delegaciones gubernamentales para tratar temas de interés planetario (Habermas, 1997, p. 78), una institución que coincide en términos generales con la idea kantiana de asociación de naciones libres, postulada como la primera fase de un largo proceso. Desde 1945, no obstante, se ha transformado intensamente el panorama de las relaciones internacionales. Asi, se ha producido, por ejemplo, un espectacular aumento del nivel global de integración gracias, en gran medida, a la intensificación de los flujos económicos y a la revolución de los medios de comunicación -que han hecho posible una multiplicación insospechada de los intercambios humanos, ampliando así inmensamente el horizonte vital de los individuos-. Habermas cree percibir en esta nueva situación un clima 
propicio para estrechar los lazos interestatales ${ }^{1.3}$, y en vista de ello hace suya una serie de propuestas de reforma de las Naciones Unidas que desde hace tiempo circulan entre la opinión pública, y de ellas selecciona aquellas que se orientan más hacia la democratización interna de la organización (Habermas, 1997, pp. 78 y 79). Su meta no es otra que la consecución de una democracia cosmopolita que gire - de momento- sobre estos tres puntos: en primer lugar, la implantación de un parlamento universal con representación directa de todos los ciudadanos del mundo; en segundo lugar, la instauración de un Tribunal de Justicia que tuviera competencia universal, y en tercer lugar, la reorganización en profundidad del Consejo de Seguridad que incluya nuevas pautas sobre la elección de los miembros, sobre el sistema de voto - con la introducción de algún elemento de ponderacióny, ante todo, sobre la capacidad ejecutiva del órgano común. Afirma asimismo que para esta amplia panoplia de reformas el funcionamiento de algunas instituciones de la Unión Europea podria servir de modelo (aunque no siempre debería ser imitado).

La cuestión no se resuelve, sin embargo, con un alarde de imaginación para diseñar nuevas instituciones; se trata más bien de mantener la aspiración moral y el carácter universalista que guiaba el proyecto kantiano. Habermas subraya, extremando así una idea que ya estaba presente en Kant ( $y$ desde base morales bien diferentes también, por ejemplo, en el proyecto de paz universal redactado por Jeremy Bentham en 1789), que sólo la vitalidad de una opinión pública que extienda sus redes por todo el planeta puede ofrecer alguna garantía a la paz perpetua (Habermas, 1997, pp. 69-70). Una democracia cosmopolita no es posible, en cualquier caso, sin el establecimiento de una sociedad civil con una trama supranacional, mundial, compuesta de asociaciones de intereses, de organizaciones no gubernamentales, de movimientos ciudadanos y, naturalmente, de un sistema de partidos. Desde esa base social podría constituirse una opinión pública de ámbito mundial y de este modo también una cultura política común. Hasta el momento, ciertamente, no se ha alcanzado ni a escala mundial, ni incluso a escala europea, «una comunicación pública que trascienda las fronteras de las hasta ahora limitadas esferas públicas nacionales» (Habermas, 1996, pp. 23 y 24). Aunque la revolución de las zelecomunicaciones puede favorecer la aceleración de este proceso, haciendo realidad la cosmópolis en forma de telépolis (en realidad, un cosmopolitismo doméstico de raiz individualista y profundamente antiestatalista, cfr. Echeverría, 1995), sería todavía algo aventurado confiar en las virtudes de las nuevas tecnologías como estímulo suficiente de la participación ciudadana no manipulada y en sus probables dotes para articular el control democrático del poder político y económico.

Habermas, en ese artículo que se acaba de citar sobre los proyectos de Constitución para la Unión Europea, alerta sobre los graves riesgos de autonomización que corren las organizaciones internacionales, una contingencia nada descartable teniendo en cuenta los antecedentes a nivel nacional, en donde la política burocratizada ha mostrado una clara propensión a la endogamia y a la más completa

${ }^{3}$ En el mismo sentido, Truyol y Serra $(1993, \mathrm{pp} .96$ y 97) sostiene que acl derecho internacional ya no puede contentarse con delimitar entre ellas [las distintas naciones, JCVA] las competencias estatales; debe enfrentarse con el establecimiento de un orden comunitario adecuado a las dimensiones del planetaw. 
autorreferencialidad. Este peligro podria conceptualizarse como una erosión democrática de los procesos de formación de la voluntad política, una erosión que avanza al mismo ritmo que los procesos de toma de decisión se alejan de los ciudadanos. La globalización de los mercados contribuye de modo significativo a la aceleración de esta tendencia. Precisamente porque este proceso de globalización conlleva la desregulación social de la economía, resulta aún más necesaria la formación de instituciones capaces de actuar en términos supranacionales para detener el desmantelamiento del Estado de Bienestar y evitar la creciente segmentación de la sociedad que puede acabar por consolidar una infraclase totalmente marginal. En cualquier caso, aún está por resolver en clave democrática las consecuencias derivadas de la creciente interdependencia de todos los pueblos.

Habermas, en su escrito sobre La paz perpetua, reserva -como hace también Rawls - un papel destacado a los derechos humanos en las relaciones internacionales. Sin embargo, aquí puede señalarse tna importante diferencia entre ambos autores. El filósofo norteamericano concibe el ius gentrum, como se recordará, comó un conjunto de principios que, aunque carentes de valor jurídico, sirven de patrón crítico para enjuiciar el derecho internacional positivo. Los derechos humanos, encumbrados por ese ius gentizm así perfilado, se convierten igualmente en principios de naturaleza más bien moral o, más exactamente, en «límites morales al pluralismo entre los pueblos». Si esto fuera así, su frecuente empleo como cobertura ideológica de las intervenciones humanitarias - tanto pacíficas como bélicassupondría de hecho una repudiable moralización de la política internacional. Esta objeción, en parte coincidente con la agria crítica vertida por Schmitt contra la moralización de los conflictos bélicos (cfr. Habermas, 1997, pp. 84-90), puede ser refutada - tal como hace Habermas-. señalando que la naturaleza de los derechos humanos es otra, puesto que en realidad ya han sido positivizados por el derecho internacional, y que su violación supone por tanto una violación del orden jurídico vigente $^{14}$. El planteamiento habermasiano enmendaría de esta manera esa importante deficiencia detectada en Rawls, que en ningún caso sería imputable a su ascendencia kantiana, por fragmentaria que sea. Habermas resulta en este punto fiel a la intención kantiana de juridificar la esfera internacional. No obstante, cabría mostrar un mayor escepticismo frente a la capacidad e idoneidad del derecho - aunque esté legitimado democráticamente- para poner en práctica por sí solo un programa tan ambicioso.

${ }_{14}$ Las intenenciones belicas humanianias, justificadas en aras de los derechos humanos, tan frecuentes en el discurso político de los últimos años, serían precisamente el blanco de las criticas de Schmitt. Sin duda, la apelación a los derechos humanos para iniciar o participar una guerra puede ser considerada como cuna recuperación actualizada de la vieja doctrina medieval de la guerra justa» (Ruiz Miguel, 1996, p. 16). Al respecto, seria oportuno diferenciar entre whacer política de derechos humanos* $y$ whacer política con los derechos humanos». No está claro, con todo, que a algunas intervenciones no armadas (que consistan, por ejemplo, en la prestación de asistencia alimenticia o sanitaria y en la protección a grupos humanos en peligro por la acción -o la inacción-gubernamental, o incluso el uso de medidas cconómicas para coaccionar a un Estado a fin de que respetc los derechos humanos) les afecte - dada su propia naturaleza - el reproche schmittiano, aunque sea cinico, de matar en nombre de la humanidad. 


\section{Kant en el panorama actual de la política intemacional: la democratización pendiente}

Tanto Rawls como Habermas afrontan, como lo hiciera Kant en su momento, los temas que conforman la actual agenda internacional desde sus respectivas coordenadas teóricas. Como Kant, tienen también la capacidad de saber tomar el pulso a la época y hallar los motivos que justifican el entusiasmo moral. Coinciden, igualmente, en contribuir a la formación y fortalecimiento de una conciencia cosmopolita que entretanto ha ganado adeptos y plausibilidad. Convergen con el amplio consenso existente, en el marco normativo, en torno a la urgencia de construir un nuevo orden mundial en el que se otorgue prioridad a los derechos humanos, a la protección del medio ambiente y a políticas que eviten la guerra y el militarismo.

Ilabermas $\mathrm{y}$, aunque de modo menos explícito también Rawls, sostienen la validez o la actualidad de al menos dos ideas centrales del texto kantiano, que se corresponderían, respectivamente, con el sentido del primero y del tercer artículo definitivo del proyecto de paz perpetua. Una idea sería, conforme al tercer artículo, la instauración del estatuto de ciudadanía internacional: el derecho de visita y la hospitalidad universal de la que hablaba Kant debe traducirse en términos prácticos, en primer lugar, en la libertad de movimiento a lo largo de todo el planeta, $y$, en scgundo lugar, en el reconocimiento de la subjetividad internacional del individuo, hasta ahora reservada a los Estados y a sus representantes oficiales. Los beneficios de la inviolabilidad diplomática deberían extenderse a todos los individuos. Con respecto al primer artículo definitivo, que como se recordará establecía que la constitución de cualquier Estado debía ser republicana, persiste, por supuesto, la demanda de ampliar y profundizar la democratización tanto en el ámbito interno de los estados miembros de la comunidad internacional — si bien Rawls se mostraría respetuoso con los Gobiernos no democráticos- como en la estructura orgánica $y \mathrm{cn}$ cl funcionamicnto de la entidad supraestatal.

El texto kantiano daba a esa cuestión una respuesta que, en términos generales, sigue siendo plausible. Me refiero a la intuición, que revela una sabiduría práctica en su autor mayor que la que sus críticos le suelen atribuir, de que el establecimiento de regímenes republicanos en el interior de los Estados representa una condición necesaria, aunque, desgraciadamente, no suficiente, para la paz perpetua: «Si es preciso el consentimiento de los ciudadanos (como no puede ser de otro modo en esta constitución) para decidir si debe haber guerra o no, nada es más natural que se piensen mucho el comenzar el juego tan maligno, puesto que ellos tendrian que decidir para si mismos todos los sufrimientos de la guerra" (Kant, 1985, p. 17). Diversos autores han resaltado que, al menos desde los inicios de este siglo, se observa una relación entre la vigencia de un régimen político democrático y la pacificación de las relaciones internacionales. Así, Rawls (1997, p. 17, nota 20), apoyándose en Michael Doyle, que se remonta en sus pesquisas hasta 1800 , cree encontrar una cierta tendencia a la ausencia de guerras entre Estados democráticos-liberales. También Habermas (1997, pp. 67-68) constata una disposición algo más pacífica en las sociedades liberales. No habría que conceder demasiada impor- 
tancia a estas observaciones empiricas y colegir de ellas el pacifismo intrínseco de los Estados democráticos, pero tampoco hay que desdeñarlas por completo, pues pueden ser un punto de partida inicialmente útil para reflexionar en torno a la estructura del sistema internacional. Entre las diversas razones, nada evidentes, que explicarían ese hecho observado deberían considerarse - como señalaba Kantlas enormes reservas que ofrece la opinión pública de un Estado democrático para entrar en guerra contra la población de otro Estado que comparte los mismos principios, reservas que obligan a agotar todas las posibilidades de acuerdo pacífico antes de abrir las hostilidades. Además - como mantenía también Kant- sólo los sistemas democráticos ponen en manos de los representantes de la ciudadanía que sufre las consecuencias de las guerras alguna capacidad de decisión, y esto significa asentar una dificultad estructural para el libre señorío de la belicosidad desbordada. Las virtudes pacificadoras de la democracia -equiparando este término, como hice ya con anterioridad, con la noción kantiana de Estado republicano-, tanto en la política interior como en la exterior, deberían, en consecuencia, ser estimuladas mediante el empuje crítico de la opinión pública. A la democratización del orden internacional podría contribuir, entre otras medidas imaginables, la concesión de un estatuto jurídico internacional a las organizaciones no gubernamentales, con representatividad adecuadamente acreditada, de modo que pudieran participar con voz y voto en los foros internacionales. Éstos adolecen -con pocas excepciones- de un déficit democrático bastante escandaloso:

«El papel dominante del Estado en la sociedad internacional, su calidad de centro de referencia para el criterio de lo que sea intemacional, no han de hacernos olvidar los demás grupos sociales que en aquélla actúan de hecho, operando, estableciendo contactos, entendiéndose o rivalizando por encima de las fronteras estatales. Estos grupos y los individuos que los integran, que constituyen el "pueblo internacional", son el elemento democrático de la sociedad internacional» (Truyol y Serra, 1993, p. 128).

En el texto rawlsiano sobre el derecho de gentes se apunta la posible dinámica del proceso planetario de democratización: la idea de un mundo estratificado políticamente formado por anillos concéntricos en torno al núcleo de los Estados liberales, al que se añadiría una capa formada por los Estados jerárquicos bien ordenados, que a su vez estaría recubierta exteriormente por los Estados jerárquicos no bien ordenados. El objetivo sería ensanchar el círculo de las naciones liberales. Esta imagen mantiene un fuerte aire de familia con la idea kantiana de formar progresivamente una federación mundial en torno a los Estados republicanos. No parece, ciertamente, realista un proceso de integración que no se apoyara en avances paulatinos tras los pasos de un grupo en cabeza más o menos reducido. Sin cmbargo, no debería olvidarse que la actual sociedad mundial se encuentra de facto dividida de modo sumamente jerárquico: el denominado Primer Mundo marca la agenda económica, social $y$, en definitiva, política, al resto del planeta. No parece que éste fuera precisamente el tipo de liderazgo en el que pensaba Kant.

La cxpansión de la democracia, que según Kant debe acompañar a la instauración de la paz, tiene que incidir tambiến en los principios estructurales del derecho internacional (la no intervención en asuntos de la jurisdicción interna, 
la igualdad soberana de todos los Estados o la cooperación entre ellos), poniendo límites a su alcance en nombre de la protección de los derechos humanos, la libre determinación de los pueblos $\mathrm{y}$, cómo no, del mantenimiento de la paz y la seguridad internacionales. Si esto se lograra, el derecho internacional podría llegar a ser un activo agente de democratización, abriendo la posibilidad de un contrato social interestatal para la defensa de la democracia que incluyera también mecanismos que evitaran su empleo como coartada a la expansión de determinadas potencias.

De la situación histórica que vivió y observó Kant desde su nido de águila en Königsberg nos separan dos siglos preñados de guerras de crueldad y capacidad destructiva inimaginable, así como de nacionalismos exacerbados. También es verdad que entretanto se han dado importantes pasos en la cooperación internacional y en la construcción de una sociedad planetaria. El colapso del modelo político y social del Ancien Régime a finales del siglo xvin condujo a la quiebra del sistema europeo de equilibrio entre las potencias; en nuestros dias asistimos al término de la guerra fría y de la política de disuasión nuclear a gran escala y con ello al fin del equilibrio bipolar. Aunque una comparación entre los respectivos escenarios políticos, actores internacionales y correlaciones de fuerzas está fuera de lugar, puede sostenerse en cambio que ambos momentos históricos representan, mutatis mutandis, un punto de inflexión que sólo cabe superar aumentando la amplitud de foco de la praxis política y así recomponer sobre nuevas bases el orden mundial. En los últimos años confluyen, como es sabido, dos tipos de procesos autónomos entre sí que apuntan simultáneamente hacia la configuración de un mundo más interrelacionado: por un lado, cambios geopolíticos de gran envergadura - I mencionado fin del enfrentamiento entre bloques- y, por otro, fenómenos de naturaleza técnica y económica - la imparable revolución de las comunicaciones-. En esta nueva situación ya no resultá una meta utópica, sino un desafío que debe ser atendido, dotar de legitimidad y medios suficientes a las Naciones Unidas y hacer del desarrollo y el respeto del derecho internacional el eje central de convivencia. En nuestros días el problema más acuciante de las relaciones internacionales no estriba en la mundialización de la economía, presentada a menudo como una fatalidad inevitable para evadir cuestiones cruciales del debate ciudadano, sino en el hecho de que tal fenómeno no vaya acompañado por la mundialización de la democracia.

\section{BIBLIOGRAFÍA}

ARAMAYo, Muguerza y RoLdÁn (eds.) (1996): La paz y el ideal cosmopolita de la ilustración, Madrid, Tecnos.

BaCHMANN, Lutz (ed.) (1996): 200 Jahre «Ewiger Friedens?, Francfort.

Bobero, Norberto (1991): El tiempo de los derechos, Madrid, Sistema.

- (1992): El problema de la guerra y las vias de la paz, Barcelona, Gedisa.

- (1994): «Democracia y sistema internacional», en Revista Internacional de Filosofia Politica, núm. 4, pp. 5-21.

Bloci, Ernst (1979): El principio esperanza, Madrid, Aguilar (3 vols.). 
Chauvier, Stéphane (1996): "Libéralisme politique et universalisme juridique. Droits des gens et droits de l'homme selon John Rawls», en Revue de Métaphysique at de Morale, núm. 2, pp. 169-188.

ECheverRia, Javier (1995): Cosmopolitas domésticos, Barcelona, Anagrama.

Espósito, Carlos D., y Peñas, Francisco J. (1995): «La justicia como equidad y el derecho de los pueblos. Dos posibles lecturas de un ensayo de John Rawls», en Revista de Estudios Politicos, núm. 87, pp. 221-237.

Galue, W. B. (1980): Filósofos de la paz y de la guerra, México, FCE, (cap. II: «Kant y la Paz Perpetuaw, pp. 25-77).

Gierke, Otto von (1995): Teorias políticas de la Edad Media, Madrid, Centro de Estudios Constitucionales.

HaBermas, Jürgen (1982): Historia y critica de la opinión pública, Barcelona, Gustavo Gili.

- (1996): "Observaciones a "¿Necesita Europa una Constitución?" ", en Debats, núm. 55, pp. $21-24$.

- (1997): «La idea kantiana de paz perpetua», en Isegoria, núm. 16, pp. 61-90.

KANT, Immanuel (1985): La paz perpetua, Madrid, Tecnos.

- (1987): Ideas para una historia universal en clave cosmopolita y otras escritos sobre Filosofia de la Iistoria, Madrid. Tecnos.

- (1989): La metafisica de las costumbres, Madrid, Tecnos.

KLENNER, Hermann (1996); «Kants Entwurf "Zum ewigen Frieden" - Illusion oder Utopic?", en Archiv für Rechts- und Sozialphilosophie, núm. 2, pp. 151-160.

Leibniz, G. W. (1984): Escritos de filosofia juridica y política, Madrid, Editora Nacional.

Maus, Ingeborg (1992): Zur Aufklärning der Demokratietheorie, Francfort, Suhrkamp.

MERKEl y WitrmanN (eds.) (1996): "Zum ewigen Frieden". Über Grundlagen, Zustand und Aussichten einer Idee von Immanuel Kant, Francfort, Suhrkamp.

Merkel, Reinhard (1996): "Lauter leidige Tröster"? - Kants Entwurf "Zum ewigen Frieden" und die Idee eines Völkerstrafgerichtshofs», en Archiv für Rechts- und Sozialphilosophie, núm. 2, pp. 161-186.

NAGEL, Thomas (1996): Iguaidad y parcialidad, Barcelona, Paidós.

Pérez LuNo, Antonio-Enrique (1992): La polémica sobre el Nuevo Mundo. Los clásicos españoles de la Filosofia del Derecho, Madrid, Trotta.

Rawls, John (1979): Teoría de la justicia, México, Fondo de Cultura Económica.

- (1985): «Justice as Faimess: Political not Metaphysical», en Philosophy and Public Affairs, núm. 14.

- (1997): El liberalismo politico, Barcelona, Crítica.

- (1997): «El derecho de gentes", en Isegoría, núm. 16, pp. 5-36.

Remiro Brotóns, Antonio (1996): Civilizados, bärbaros y salvajes en el muevo orden internacional, Madrid, McGraw-Hill.

RoRTy, Richard (1994): «Menschenrechte, Vernunft und Empfindsamkeit», Transit, núm. 7, pp. 102-121.

Rousseau, Jean-Jacques (1982): Escritos sobre la paz y la guerra, Madrid, Centro de Estudios Constitucionales.

Ruiz Mrguel, Alfonso (1988): La justicia de la guerra y de la paz, Madrid, Centro de Estudios Constitucionales.

- (1996): «Las intervenciones bélicas humanitarias», en Claves de la razón práctica, núm. 68 , pp. 14-22.

Scimitr, Carl (1979): El Nomos de la Tierra en el Derecho de Gentes del alus Publicum Europaeum», Madrid, Centro de Estudios Constitucionales.

Thiebaut, Carlos (1984): «Las racionalidades del contrato social: Kant en Rawls», en Zona Abiena, núm. 32, pp. 117-159. 
- (1994): «Democracia y diferencia: un aspecto del debate sobre el multiculturalismo», en Anales de la Cátedra Francisco Suárez, núm. 31, pp. 41-60.

Truyol y Serra, Antonio (1979): «La Guerra y la Paz en Rousseau y Kant», en Revista de Estudios Politicos, núm. 8 (nueva época), pp. 47-62.

- (1993): La sociedad intemacional, Madrid, Alianza.

Vauespin, Fernando (1995): «Diálogo entre gigantes: Rawls y Habermas», en Claves de la razón práctica, núm. 55 , pp. $48-55$.

VATTEL, Emmer de (1758): Memoires politiques concemant la guerte et la paix, ou principes de la loi naturelle apliqués à la conduite et aux affaires des nations et des souverains, Francfort/Leipzig, Aux Depens de la Compagnie, 2 vols.

Walzer, Michael (1995): «Las razones para intervenir», en Letra Intemacional, núm. 40, pp. 16-21. 


\section{La balsa ol

Número 40

\section{REVISTA TRIMESTRAL}

A. de Prada, De sabios e idiotas. Notas sobre la abstención. G. Abril, La cultura masiva entre el espectáculo y el ritual. P. C. Sutton, Elementos rituales de la ópera rock. R. Quance, Frida Kablo, o la aniquilación de la madre. M. Valdivieso, Lucia Moholy, el ojo anónimo que retrató la Bauhaus. R. Navarrete-Galiano, "Realidad». Galdós y su novela con trasfondo homosexual. J. Seoane Pinilla, ¿Atender a nuestra experiencia? V. Bozal, La literatura del pobre. Documentos, Encuentro internacional por la Humanidad y contra el Neoliberalismo, Chiapas, 1996.

Edita Visor Dis., S. A.

Redacción, administración y suscripciones

C/ Tomás Bretón, 55

Teléfono 4681102

28045 MADRID

Precio del ejemplar, 800 pesetas. Precio número doble, 1.600 pesetas.

Suscripción anual (4 números): España, 2.900 pesetas.

Europa, 4.000 pesetas. América, 4.500 peseras. 